\title{
Mitigating the impacts of fragmented land tenure through community-based institutional innovations: two case study villages from Guinan County of Qinghai Province, China
}

\author{
Gongbuzeren $^{1}$, Jing Zhang $^{2}$, Minghao Zhuang $^{3}$, Jian Zhang $^{4,5}$ and Lynn Huntsinger $^{6}$
}

\begin{abstract}
The privatization of collectively used rangelands results in fragmentation of land use in pastoral areas. This affects pastoralists' grazing strategies and results in new institutional arrangements for addressing changing social-ecological systems. Two main systems of grazing management have emerged in the pastoral regions of the Qinghai-Tibetan Plateau that offer new perspectives on addressing rangeland fragmentation. One allows the renting of parcels of allocated grazing land to or from others (RTS) and is based on having fenced contracted parcels for each household. The other is a community-based grazing quota system (GQS) in which a grazing use quota is allocated to each household, while the community maintains collective use of the rangeland. We compare two case study villages implementing these two different management systems, operating across household and community scales, and analyze vegetation composition, above-ground biomass, and soil properties as indicators of impacts. Transects reveal that aboveground biomass was higher under the RTS than under the GQS, but species composition shifted to dominance by non-palatable forbs and graminoids. The RTS grasslands had lower carbon and nitrogen density compared to GQS-managed grasslands. These differences are consistent with the herder's perceptions of ecological changes. The general improvement of rangeland conditions under the GQS may be linked to greater herd mobility and the control of livestock numbers through the establishment of community-enforced grazing quotas. Mobility under the RTS is limited to a few parcels, and local regulation of stocking rates is minimal because the system relies on external intervention. The case of GQS suggests that addressing rangeland fragmentation with improved vegetation conditions requires institutions operating at both household and community scales allowing for mobility and regulation of stocking rates.
\end{abstract}

Key Words: community-based management; grazing quota system; institutional scale; rangeland land tenure; rangeland transfer

\section{INTRODUCTION}

In much of the world, market-based economic reform has led to policies seeking the privatization of collectively used and managed rangeland (Behnke and Scoones 1993, Li and Zhang 2009) in an effort to avoid the long debunked but persistently referenced "tragedy of the commons" (Ostrom 1990) and stimulate private investment in the land. When allocated pastures are fenced, land use as well as tenure is fragmented, generating unprecedented uncertainties that are characterized in reduced livestock mobility (Scoones 1994), increased livestock production costs (Li and Zhang 2009, Gongbuzeren et al. 2016), fragmented community social networks and reciprocity ( $\mathrm{Li}$ and Huntsinger 2011), increased livelihood vulnerability (Yeh et al. 2014, Scoones 2015), and enhanced levels of rangeland degradation (Cao et al. 2013, Harris et al. 2016, Li et al. 2018). Although there is a rich literature documenting the challenges of rangeland fragmentation, the question of what institutional innovations might respond to sustain pastoral livelihoods and environments are rarely addressed.

Processes of social-ecological interaction in pastoral regions occur at multiple scales and rangeland fragmentation has a major impact on scalar interactions. On the one hand, the spatial and temporal distribution of grassland resources are heterogenous on the alpine steppes and in arid and semi-arid regions (Hobbs et al. 2008, Lai and Li et al. 2012), and the heterogeneity of rangeland ecosystem and local climatic conditions have increased rapidly under recent climate change (Chen et al. 2017). In this sense, many other studies (McAllister et al. 2006, Hobbs et al. 2008, Harris et al. 2016) point out, rangeland institutions that restore larger spatial scales of livestock movement and improve resource tracking can be effective in maintaining access to resource heterogeneity and reduce the need for inputs and associated costs. On the other hand, recent studies also show that the necessary scale for rangeland management is also determined by changes in socioeconomic conditions. Markets for livestock and livestock products are expanding rapidly (Zhang et al. 2014, Chinasho et al. 2017, Han 2018), and the products and services that herders can market from rangelands have diversified under market-based economic reforms, including medicinal herbs, ecotourism, cultural products, and handicrafts (Gongbuzeren et al. 2018). Many poor families with few or no livestock have demanded changes in household contracts to achieve a more equal distribution of rights over resource access (Gongbuzeren et al. 2018, Li et al. 2018). In this sense, even though studies pointed out that that the economic inputs needed will increase with decreased enterprise scales that encompass less resource heterogeneity (Hobbs et al. 2008, Ulambayar and FernandezGimenez 2019), institutions focusing on the household scale may better help the local individual households to achieve equal distribution of rangeland resources.

Given these social-ecological dynamics, a focus on multiple institutional scales is essential. In this study, we asked how institutions operating at the household and community scales can interact to adapt to the changing ecological and socioeconomic

${ }^{1}$ Southwestern University of Finance and Economics, ${ }^{2}$ Beijing Forestry University, ${ }^{3}$ China Agricultural University, ${ }^{4}$ Academy of Macroeconomic Research, NDRC, ${ }^{5}$ Institute of Spatial Planning and Regional Economy(ISPRE), NDRC, ${ }^{6}$ The University of California, Berkeley 
landscapes, and in particular rangeland fragmentation. By exploring two contrasting institutional responses in the QinghaiTibetan Plateau (QTP), the rangeland transfer system (RTS) and community-based grazing quota system (GQS), new insights into how institutions operating at different scales result in different ecological outcomes are revealed.

In the pastoral regions of the QTP, the land allocations of the rangeland household contact policy began in the early 1990s and, where the household pastures have been fenced, ecological conditions have been changing. Identified ecological changes include plant compositional changes with replacement of palatable species by nutrient-deficient or toxic species (Zhou et al. 2005, Li and Huntsinger 2011), gradual destruction of the turf layer and decline of above-ground biomass (Dong et al. 2013), and fragmentation of extensive wildlife habitat and migration corridors (Fox et al. 2009, Jakes et al. 2018). Studies have also found that fragmentation constricts the herder flexibility needed because of the ecological variability and extreme weather conditions (Banks et al. 2003, Yan et al. 2005, Li and Huntsinger 2011, Yeh et al. 2014, Gongbuzeren et al. 2015). Socioeconomic implications include increased livestock production costs ( $\mathrm{Li}$ and Zhang 2009), livestock mortality, and internal community conflict over fence boundaries (Yan et al. 2005, Yeh and Gaerrang 2011).

To address some of the issues arising from land division, China has been promoting an RTS since 2008, allowing households to rent their contracted rangelands to others. Since the Third Plenary Session of the Seventeenth Central Committee promoted "Decision Rural Reform and Development" discussing the various conditions for completion of the land rental system in agricultural regions, many pastoral communities, which contracted their rangelands into individual households with fence building, started practicing the rangeland transfer system and have been supported by local government (State Council 2008, QPG 2011). In 2016, when the Chinese government launched "Separating Three Property Rights" reform, acknowledging three types of property rights: non-tradable ownership (generally by the state), non-tradable contracted rights, and tradable land-use rights (State Council 2016), the rangeland transfer system has been officially enacted and has been promoted to all the pastoral regions. This policy encourages herders to augment their household grasslands by renting from those without enough livestock to use their allocations, or those who have quit, or have retired from grazing (Gongbuzeren et al. 2016). Those renting grasslands to others can earn an income, even with no livestock. The RTS is a tradable land-use right.

In some areas of the QTP, despite the strong influence of policy interventions, community self-organized innovative grazing management institutions have arisen to manage the rangelands (Lai and Li 2012, Cao et al. 2013, Gongbuzeren 2019). One of these innovative grazing management systems includes a community-based GQS that retains community collective use of rangelands while privatizing the use right of grazing, allowing contracted land to remain in collective management without fences (Gongbuzeren et al. 2018). The GQS is a self-organized community system that stipulates grazing quotas at the household level to control livestock numbers while maintaining greater livestock mobility at the community scale. Households can sell, lend, and trade livestock grazing quotas, but the rangeland is used collectively and cannot be alienated or rented. Enforcement of livestock number limits is done by the community because members have a common interest in protecting the pasture. When the pasture is in good condition, quotas can increase for all.

Among the two most prominent ways of retaining or restoring larger herding areas, the RTS allows the transfer of grazing use rights to other herders through leasing fenced pastures, whereas the GQS allows the transfer of the right to graze a certain number of animals (a quota) to other herders but leaves the land undivided and under community management, although notionally allocated on paper. The goal of both systems is to recapture some of the ecological, social, and economic benefits of the traditional large-scale herd movements that once were a fundamental pastoral practice in the region. The RTS can be seen as a way to re-aggregate use of some of a community's fragmented pastures, whereas the GQS prevents or replaces the fragmentation of land use on all of the community's shared pasture.

Although the impacts of these new systems in response to land fragmentation (operating at household and community scales) on livestock production and herder livelihoods have been studied (Gongbuzeren and Li 2016, Zhuang et al. 2017, Gongbuzeren 2019), the changes these systems bring to rangeland ecosystems and soil properties remain undocumented. This is the focus of our research. The RTS and GQS affect patterns of livestock movement temporally and spatially, with direct implications for rangeland ecosystems. Although ecological studies have explored the impacts of climate change and grazing exclusion on vegetation and soil (Klein et al. 2007, Sang 2009, Harris et al. 2015, 2016, Su et al. 2015, Wang et al. 2017, Hopping et al. 2018), many studies only examine the impacts of grazing versus no grazing under different climatic conditions and take no account of the institutional conditions and their operation at different scales. This study compares two cases, with different institutional arrangements for responding to land fragmentation due to privatization. Village A uses RTS as the dominant strategy for managing grazing use and Village $B$ uses the GQS. Both field and interview research were used to assess impacts. Although our study is limited to the summer pastures of two villages, we believe it offers insight into the consequences of these two institutional models for managing fragmented grasslands in pastoral areas.

\section{METHODS}

The two selected case study villages have similar environmental characteristics (Tables 1,2) and traditionally had collective use of three seasonal grazing areas, including summer pastures, middle pastures (used for spring and fall grazing), and winter pastures. Today, the two villages now use different strategies to manage grazing. Data were gathered through interviews and field surveys to compare ecological and livestock management outcomes in each village.

\section{Study area}

Villages A and B are located in Guinan County, Qinghai Province, P. R. China (Fig. 1). The two villages are $50 \mathrm{~km}$ from each other and are in most ways quite similar (Tables 1,2). Village A grazing lands were allocated and contracted to individual households under the rangeland household contract policy (RHCP) beginning in 1999 (Table 3). Households fenced their allocated winter pastures with wire fences on a household by household 
Table 1. Socioeconomic characteristics of Village A and Village B. Note: RTS = rangeland transfer system, GQS = grazing quota system.

\begin{tabular}{|c|c|c|c|c|c|c|c|}
\hline & Population & Household & Sheep & Yak & Sheep units $^{\dagger}$ & $\begin{array}{l}\text { Livestock income/Total } \\
\text { household income }\end{array}$ & $\begin{array}{l}\text { Sheep units per } \\
\text { capita }\end{array}$ \\
\hline Village A (RTS) & 440 & 106 & 11,318 & 1388 & 18,258 & $78 \%$ & 42 \\
\hline Village B (GQS) & 2000 & 431 & 60,000 & 6000 & 90,000 & $76 \%$ & 45 \\
\hline
\end{tabular}

${ }^{\dagger}$ Sheep units is the unit being used to measure the total livestock numbers that each family owns. Under this, 1 yak is equal to 5 sheep units.

basis. They combined their summer and middle pastures and allocated one large grazing parcel to each individual household (Gongbuzeren and Li 2016) but did not fence these units by individual household at the time. Instead, until 2008, groups of 3-10 families collectively used large sections of the village summer and winter pastures. Beginning in 2008, as the government began promoting the rangeland transfer system, Village A fenced individual household allocations with wire fences on all pastures, allowing households to rent individual parcels in accordance with the RTS. As Table 3 demonstrates, all the grasslands were then controlled and used by individual households or their tenants.

Fig. 1. Location of the two study sites, Village A (lower) and Village B (upper) in Guinan County, Qinghai Province, P. R. China.

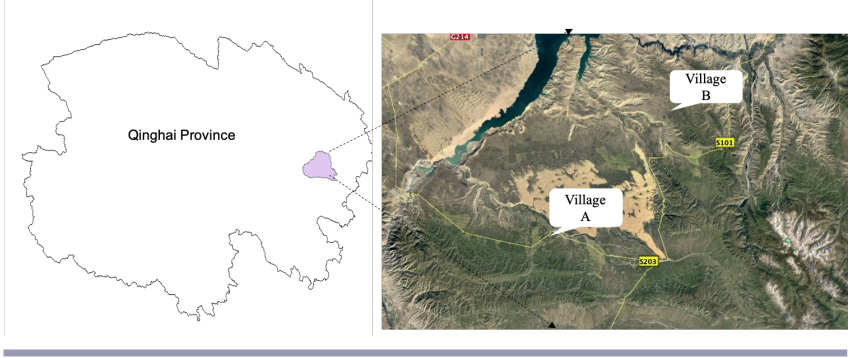

The implementation of the RTS, operating principally at the household scale, has reshaped patterns of livestock movement. First, as Village A combined their summer and middle (spring/ fall) pastures, they reduced their three seasonal movements to two. This means that the herders keep their yaks on summer pasture from June $20^{\text {th }}$ to early October, more than 120 days, depending on parcel forage availability. Sheep are on summer/ middle pasture from June $20^{\text {th }}$ to August $20^{\text {th }}$, a total of 90 days, a longer period than before. Second, under the RTS, herder demand for grazing land rentals has increased rapidly. According to our survey, the percentage of households that rented rangelands from others in Village A increased from 53\% in 2012 to $82 \%$ in 2014, and some rented pastures are outside of the village. According to herder interviews, over $90 \%$ of rented parcels are under short-term leases of one to three months, and each parcel is rented out to several families within a year. Consequently, grazing duration in these short-term rented grazing parcels has increased to nine months.

By contrast in Village B, although each household has a paper contract from the government indicating the location and size of their allocated individual grazing parcels, they only fenced the individual parcels on their winter pastures and still used their summer and spring pastures collectively. In 2009, Village B implemented a GQS institutional arrangement, operating at both household and the community scales, to manage these pastures. The community collectively sets individual grazing quotas that limit the total number of livestock that each household can graze. To establish a community grazing capacity, when the village moves to the spring/fall and summer pastures, the community relies on traditional governance practices to collectively estimate the total carrying capacity of the seasonal pasture based on their experience-based knowledge of local rangeland conditions and annual weather patterns. The quota standards change every year based on the conditions of the rangelands. The community pools all their grazing quota systems and each household is allocated a share of the carrying capacity based on the carrying capacity for the number of hectares allocated in their HRS paper contracts. Each year, a committee of village leaders and respected elders count and monitor each household's livestock when they migrate to the seasonal pastures, and each household is required to make a vow to not cheat on the livestock number, in accordance with local culture about the sanctity of certain kinds of vows. The committee charges a fee to households whose livestock numbers exceed their grazing quota and distribute the money as compensation to households using less than the quota, so that households without enough livestock still have an income. The community collectively decides on the amount of the fee (Gongbuzeren et al. 2018). The GQS clarifies tradeable rights within the community to a share in the grazing quota at the individual household scale so that herding households can maintain mobility, community management practices, and shared labor at the community scale.

There are comparatively fewer changes in the patterns of livestock mobility from more traditional systems under the GQS. First, because they have seasonal livestock mobility, and villagers only spend 50 days of grazing time in their summer pasture per year, which is less than that of Village A. Second, herders also stated that growing demand for livestock products put pressure on herders to increase livestock numbers, but that the GQS keeps individual households from expanding their livestock numbers beyond the land's carrying capacity. According to our survey, the average number of household sheep units dropped slightly from 264 sheep units/household in 2012 to 252 sheep units/household in 2014. Third, because their summer and middle pastures are collectively used, these two seasonal pastures were never under the rental system as happened in Village A.

\section{Ecological field studies}

To understand rangeland ecosystem changes under different management institutions operating at different scales, we conducted ecological sampling in the summer pastures to examine 
Table 2. Ecological conditions of the sampling sites in the summer pastures of the two villages and the 2003 study site by Yang (Yang 2008).

\begin{tabular}{|c|c|c|c|}
\hline Ecological conditions of the sampling sites & Village A & Village B & 2003 \\
\hline Location & Guinan County & Guinan County & Guinan County \\
\hline Biome & Alpine meadow & Alpine meadow & Alpine meadow \\
\hline Vegetation type & Kobresia pygmaea & Kobresia pygmaea & Kobresia pygmaea \\
\hline Rangeland type & Summer pasture & Summer pasture & Summer pasture \\
\hline \multirow[t]{2}{*}{ Location } & $35^{\circ} 23^{\prime} 418^{\prime \prime} \mathrm{N}$ & $35^{\circ} 39^{\prime} 925^{\prime \prime} \mathrm{N}, 101^{\circ} 14^{\prime} 041^{\prime \prime}$ & $35^{\circ} 57^{\prime} 452^{\prime \prime} \mathrm{N}, 100^{\circ} 78^{\prime} 049^{\prime \prime}$ \\
\hline & $101^{\circ} 18^{\prime} 597^{\prime \prime} \mathrm{E}$ & $\mathrm{E}$ & $\mathrm{E}$ \\
\hline Total rangeland area/ha & 5334 & 15333 & - \\
\hline Rangeland area per capita/ha & 12 & 8 & - \\
\hline Elevation of the sampling sites & $3800 \mathrm{~m}$ & $3690 \mathrm{~m}$ & $3304 \mathrm{~m}$ \\
\hline Slope degree of the sampling sites & $15^{\circ}$ & $11^{\circ}$ & $12^{\circ}$ \\
\hline Aspects of the sampling sites & Northwest $309^{\circ}$ & North $340^{\circ}$ & \\
\hline Annual average precipitation & $405.8 \mathrm{~mm}$ & $405.8 \mathrm{~mm}$ & $405.4 \mathrm{~mm}$ \\
\hline $\begin{array}{l}\text { Average number of pika burrows in sampling sites (number in per } \\
\text { sampling sites) }\end{array}$ & 43 & 21 & - \\
\hline Average annual temperature & $3.1^{\circ} \mathrm{C}$ & $3.12^{\circ} \mathrm{C}$ & $3.05^{\circ} \mathrm{C}$ \\
\hline \multirow[t]{3}{*}{ Grazing duration in summer pasture } & 120 days for yak & 50 days for sheep and yak & Community collective use \\
\hline & 90 days for sheep & No rental system & with seasonal mobiltiy \\
\hline & Under rental system & Quota control & \\
\hline
\end{tabular}

changes in vegetation composition, aboveground biomass, and soil properties. We complemented this with semi-structured household interviews to understand herder perceptions of ecological change. Empirical field data on vegetation and soil properties from July $3-30^{\text {th }} 2014$ were compared with baseline data collected in 2003. These two approaches provided a multidimensional picture of the changes in rangeland ecosystems and their impacts.

\section{Household interviews}

Herders make long-term and continuous observations of changes in ecological and animal conditions, and herder interviews can help understand how ecological changes might affect livestock and how herders perceive ecological conditions. Based on herd size, a stratified random sampling method was applied to select an equal proportion of comparatively rich, medium-wealth and poor households based on village records of household holdings. A total of 20 households from each village, $21 \%$ of the total households in Village A and $11 \%$ in Village B, were interviewed. The interviewees were asked detailed questions about their perceptions of changes in ecological conditions, including vegetation heights and density, the area of bare ground, level of diversity and productivity, number of poisonous plant species, and the level of disturbance by the pika (Ochotona spp.) a small burrowing lagomorph believed to be associated with heavy grazing and erosion. According to our interview with the local herders, these indicators of ecological changes are commonly being observed in their daily lives to assess rangeland conditions, and also these indicators are being adopted by many previous studies to measure the level of rangeland degradation and ecological conditions (Cao et al. 2013, Gongbuzeren et al. 2018).

\section{Field transects in summer pastures}

The pastures in our two case study sites can be categorized into two main grassland types: winter pastures are a mixture of alpine desert and alpine steppe with dominant species including Stipa purpurea and Carex moorcroftii; summer and middle pastures are alpine meadow with dominant species including Kobresia pygmaea and K. humilis (Yang 2008, Gongbuzeren and Li 2016). We selected the summer pastures of the two villages to conduct our plot samplings because the differences in patterns of livestock mobility and grazing pressure under different management institutions are more obvious in summer pastures, and also because their summer pastures shared higher levels of similar ecological conditions for comparative studies. We collected our plot samples in early July before herds moved to the summer pastures. The summer pastures are mountainous alpine meadows with average elevations reaching $3600 \mathrm{~m}$. Herders camp in the mountain valleys, and their livestock move vertically from the lower areas of the mountain slopes to the top of the mountains during the day and return to camp in the evening. Therefore, we laid out our plots along an elevation gradient from the camp area up the mountain slopes.

The two villages share very similar ecological features (Table 2), allowing direct comparison of vegetation and soil qualities. In Village A, we selected three summer pasture sampling sites on sunny slopes in the pastures of three different households under short-term leases to different households over the course of a year. Although we established three $1000 \mathrm{~m}$ transects on the elevational gradient at each sampling site, the slope ranged between 10-15 degrees with elevational differences between the two sites being very small (see Fig. 2). Therefore, the influence of elevational gradient on vegetation and soil properties is thought to be negligible. Along each transect, we established three $15 \mathrm{~m} \mathrm{x} 15 \mathrm{~m}$ plots at a distance of every $300 \mathrm{~m}$ along the line. Within each of these plots, we randomly selected six $1 \mathrm{~m}$ x $1 \mathrm{~m}$ quadrats. In total, we sampled $1621 \mathrm{~m} \times 1 \mathrm{~m}$ quadrats on three transects at each of three sampling sites. Soil samples were taken in each plot at depths of 0-10 cm, 10-20 cm, and 20-30 cm. Bulk density samples were obtained using a standard container with a fixed volume size of $100 \mathrm{~cm}^{3}$.

In Village B, because the summer pastures were not divided, we randomly selected three sampling sites on the sunny slopes of the shared summer pasture and established $1000 \mathrm{~m}$ transects in each 
Table 3. Scale and grazing management institutions. Note: RTS = rangeland transfer system, GQS = grazing quota system, RHCP = rangeland household contract policy.

\begin{tabular}{|c|c|c|}
\hline & Village A (RTS) & Village B (GQS) \\
\hline Community scale & & $\begin{array}{l}\text { Collective decisions and monitoring on resource access and } \\
\text { use, fees for excess stock and setting quota; } \\
\text { Grazing quota shares and trades limited to community } \\
\text { members; } \\
\text { Three season movements and use of larger collective summer, } \\
\text { spring/fall grazing areas; } \\
\text { Shared labor and greater mobility. }\end{array}$ \\
\hline Household scale & $\begin{array}{l}\text { Household decides on the use, allocation, and rental of } \\
\text { individual grazing parcels; } \\
\text { Access open to anyone who is able to rent land; } \\
\text { Livestock mobility is among parcels: the herder's allocated } \\
\text { parcel and those the herder can rent. }\end{array}$ & $\begin{array}{l}\text { Grazing quota share is a clarified right of the household and } \\
\text { can be traded via community facilitation; } \\
\text { Household quota is tied to original land allocations through } \\
\text { RHCP; } \\
\text { Winter pastures are fenced and used by individual households. }\end{array}$ \\
\hline
\end{tabular}

on a similar elevational gradient. As with Village A, we selected three $15 \mathrm{~m}$ x $15 \mathrm{~m}$ plots along each transect, and then within each of these large plots we randomly selected six $1 \mathrm{~m}$ x $1 \mathrm{~m}$ quadrats and collected soil and vegetation samples.

Fig. 2. A photo of pasture from the study site to show the similarities of vegetation characteristics along the elevation gradient.

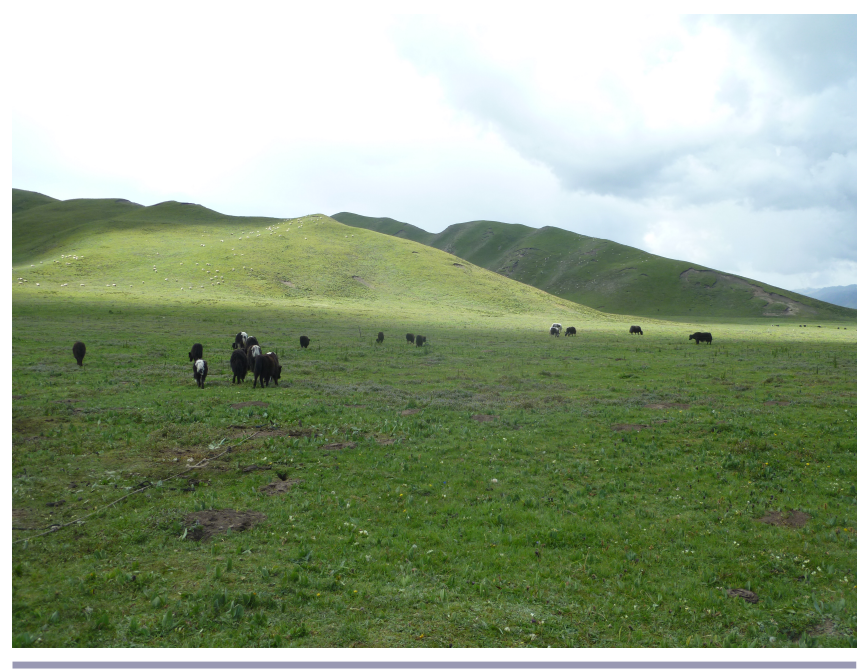

\section{Measurements}

We categorized the vegetation into three main groups based on livestock preferences: (1) palatable graminoids, such as Kobresia humilis, Kobresia parva, and Stipa capillata; (2) palatable forbs, such as Potentilla nivea and Salsola collina Pall.; and (3) nonpalatable forbs and graminoids, such as Elsholtzia densa Benth., Achnatherum splendens, and Stellera chamaejasme. Increases in non-palatable plants were also identified as indicators of rangeland productivity decline because of a lower contribution to livestock production.

For analyses of changes in vegetation, we measured species richness and canopy cover of each vegetation type and aboveground biomass on the two sites. For measurement of aboveground biomass, we collected the aboveground biomass from each quadrat, oven dried it at $75^{\circ} \mathrm{C}$ to a constant mass, and weighed it.

For analyses of changes in soil properties, we mainly assessed carbon and nitrogen density, and provided measurement of soil bulk density, water content, and soil fractal dimension in supplemental data for further information. The soil samples were filtered through a $2 \mathrm{~mm}$ mesh to remove the roots and the stones. Soil organic carbon and soil total nitrogen were measured by oxidization with $\mathrm{K}_{2} \mathrm{Cr}_{2} \mathrm{O}_{7}$ and 2400 II CHNS/O Elemental Analyzer (Perkin-Elmer, USA). Then, the soil samples were ovendried at $105{ }^{\circ} \mathrm{C}$ to a constant mass and weighed. We then calculated the soil water content by soil moisture (namely, soil fresh weight minus soil dry weight) divided by fresh soil weight (Bao 2000), and calculated soil fractal dimension by using equation 3 (Tyler and Wheatcraft 1989). These methods are similar to those Yang (2008) applied in his study.

Soil organic carbon density was calculated by using equation (1).

$$
\mathrm{SOCD}=\mathrm{SOC} \times \mathrm{BD} \times \mathrm{De} \times 10
$$

Where SOCD (STND) is the soil organic carbon density (soil total nitrogen density) in g. $\mathrm{cm}^{-2}$, SOC (STN) is the soil organic carbon content (soil total nitrogen content) in $\mathrm{g}_{\mathrm{kg}} \mathrm{kg}^{-1}, \mathrm{BD}$ is the bulk density in $\mathrm{g} . \mathrm{cm}^{-2}$, and De is the soil depth in $\mathrm{cm}$.

Soil total nitrogen density was calculated by using equation (2).

$$
\mathrm{STND}=\mathrm{STN} \times \mathrm{BD} \times \mathrm{De} \times 10
$$

Soil fractal dimension (D) was calculated by using equation (3).

$$
\frac{V\left(r<R_{i}\right)}{V_{T}}=\left(\frac{R_{i}}{R_{\max }}\right)^{3-D}
$$

Where $\mathrm{D}$ is soil fractal dimension, $V\left(r<R_{i}\right)$ is the cumulative mass of particles of $i$ th size $\mathrm{r}$ less than $R_{i}, V_{T}$ is the total mass, $R_{i}$ is the mean particle diameter $(\mathrm{mm})$ of the ith size class, and $R_{\max }$ is the mean diameter of the largest particle.

We applied historical data of ecological conditions that were documented in Guinan County by Yang et al. (2008) in 2003 as a control to further assess the possible changes in grassland 
vegetation and soil structure in our two case study sites. Although Yang's sampling site was a different case village in Guinan County, we believe it offers viable baseline data for a comparison of changes for the following reasons. First, the GPS location of the 2003 control site indicates that it was located in Guinan County, very close to our two case study sites (Table 2), and the ecological features including elevation, rangeland type, grazing management system, and geographical features of the study sites where Yang conducted his vegetation sampling were quite similar to our two case villages (Table 2). Second, our studies discovered that even though the government promoted the rangeland household contract policy in the late 1990s, many pastoral communities did not implement this policy in practice until the early 2000s. In 2003, both case villages applied community collective use of rangelands with three-four seasonal livestock mobility because the rangeland household contract policy was only just beginning to be implemented. The 2003 study by Yang is the only accessible data that are currently available to show the rangeland conditions before the implementation of the rangeland household contract policy. Third, we also compared the meteorological conditions in Guinan County in 2003 with 2014, the year our plot samples were collected, and results demonstrated that climatic characteristics were similar during the two years (Table 4). Despite these similarities, we do acknowledge that there are some big gaps in making this type of comparison with historical data, and any potential site-based biophysical and ecological differences that we were unable to capture could affect the findings of this paper. But at the same time, this is also the only accessible and available historical dataset that we could use to understand the vegetation and soil conditions in Guinan County before the implementation of the rangeland household contract policy.

Table 4. Average temperature and precipitation during the growing season and for the year in Guinan County (http://data. cma.cn/).

\begin{tabular}{cccccc}
\hline \hline Year & \multicolumn{2}{c}{ Average temperature $\left({ }^{\circ} \mathrm{C}\right)$} & & \multicolumn{2}{c}{ Average precipitation $(\mathrm{mm})$} \\
\cline { 2 - 3 } \cline { 5 - 6 } & Growing season & Annual & & Growing season & Annual \\
\hline 2003 & 11.42 & 3.05 & & 375.4 & 405.4 \\
2014 & 11.35 & 3.16 & & 383.9 & 405.8 \\
\hline
\end{tabular}

The SPSS ver. 17.0 statistical software (SPSS Inc., Chicago, Illinois, USA) was used to perform one-way analyses of variance (ANOVA) for all parameters (aboveground biomass, soil bulk density, soil water content, soil fractal dimension, soil organic carbon density and nitrogen density) among all treatments. We first averaged all of the plots in each transect, and then used ANOVA to compare the differences of vegetation and soil structures between different management systems. The results indicated that there was significant difference among 2003 GQS and RTS at the level of 0.05 , and vice versa.

\section{RESULTS}

There were important differences in herder perceptions of ecological conditions and in the results of field sampling across the two types of institutional arrangements and over time.

\section{Herder perceptions of ecological change}

According to herder perceptions (Table 5), 35\% of herders using the GQS reported a decrease in vegetation growth after implementation of the system, although the rest reported an increase or no change, whereas $65 \%$ of the herders using the RTS reported a decrease in vegetation growth after system implementation. Similarly, the majority $(46 \%$ and $65 \%)$ of the herders in GQS reported no changes in vegetation density and diversity, whereas $71 \%$ and $59 \%$ of the herders under RTS reported decreases in vegetation density and diversity. However, there were also over $50 \%$ and $82 \%$ of herders in both GQS and RTS who reported a decrease in vegetation heights. In terms of other ecological indicators, $40 \%, 30 \%$, and $30 \%$ of interviewed herders using the GQS reported an increase in the amount of pika disturbance to soil, bare ground, and poisonous species, respectively. The rest reported an improvement or no change. Under the RTS, $64 \%, 65 \%$, and $65 \%$ of the interviewed herders reported an increase from pika disturbances to soil, bare ground, and poisonous species, respectively. The rest reported an improvement or no change.

Table 5. Herder perceptions of rangeland ecological conditions under the community-based grazing quota system (GQS, $n=30$ households) and the rangeland transfer system (RTS, $n=20$ households) in 2014.

\begin{tabular}{llccc}
\hline \hline Village & Indicator & \multicolumn{3}{c}{ Herder response (\%) } \\
\cline { 3 - 5 } & & 19 & 35 & 46 \\
\hline \multirow{2}{*}{ GQS } & vegetation growth & 19 & 50 & 31 \\
& vegetation height & 12 & 42 & 46 \\
& vegetation density & 8 & 27 & 65 \\
& vegetation diversity & 40 & 15 & 45 \\
& Pika & 30 & 15 & 55 \\
& bare ground & 45 & 19 & 36 \\
& poisonous species & 18 & 47 & 35 \\
RTS & vegetation growth & 6 & 82 & 12 \\
& vegetation height & 0 & 71 & 29 \\
& vegetation density & 12 & 59 & 29 \\
& vegetation diversity & 64 & 12 & 24 \\
& Pika & 65 & 6 & 29 \\
& bare ground & 65 & 15 & 20 \\
\hline & poisonous species & & &
\end{tabular}

In short, although there was some level of perceived degradation observed under the GQS, the majority of herders observed no changes in rangeland conditions, whereas the majority of the herders observed deterioration after implementation of the RTS.

\section{Vegetation composition and aboveground biomass}

Species richness under both the GQS and RTS was lower in comparison with the 2003 baseline, and the average number of species per sampling site under the RTS was lower than in the GQS (Table 6). In addition, the baseline vegetation cover showed that the dominant vegetation cover in Guinan's pastoral areas was palatable graminoids and forbs, with only $1.2 \%$ cover of nonpalatable plants in 2003. In 2014, the dominant vegetation cover under the GQS was still graminoids and palatable forbs at $41.1 \%$ and $28.9 \%$, respectively and the cover of non-palatable plants was $10 \%$. However, under the RTS, non-palatable plants were most of the cover at $34.2 \%$, whereas palatable graminoids and forbs were $25 \%$ and $27 \%$, respectively.

In short, even though the cover of non-palatable plants increased under both GQS and RTS, the vegetation composition remained dominated by graminoids and palatable forbs under the GQS, whereas under the RTS, the vegetation composition shifted to 
Table 6. Species richness and vegetation cover on summer pasture at baseline in 2003, and under the community-based grazing quota system (GQS) and rangeland transfer system (RTS) in $2014(\mathrm{n}=9)$. “ \pm ” represents standard deviation.

\begin{tabular}{llccc}
\hline \hline Indicator & & 2003 & GQS & RTS \\
\hline Mean species richness & & $15.2 \pm 2.17$ & $11.44 \pm 2.35$ & $7.22 \pm 1.39$ \\
Vegetation cover values & Graminoids & $30.6 \pm 7.37$ & $41.11 \pm 6.97$ & $27.83 \pm 16.86$ \\
& Palatable forbs & $12.8 \pm 2.49$ & $28.89 \pm 7.41$ & $27 \pm 8.77$ \\
& Non-palatable forbs and & $1.2 \pm 0.45$ & $10 \pm 0.01$ & $34.86 \pm 15.85$ \\
& graminoids & & & \\
\hline
\end{tabular}

dominance by non-palatable forbs and graminoids such as Rheum spp., and Elsholtzia densa, whereas the cover of palatable graminoids such as Kobresia humilis and Stipa krylovii was relatively low (Table 6).

The average aboveground biomass under the GQS and the RTS has increased in comparison to the baseline in 2003 (Fig. 3). Compared with the GQS, the average aboveground biomass under the RTS was significantly higher $(P<0.05$; Fig. 3 ; $\mathrm{n}=9)$, and we believe this may be attributed to the dominance of nonpalatable forbs and graminoids under RTS.

Fig. 3. The aboveground biomass of summer pasture at baseline in 2003 and under the community quota system (GQS) and rangeland transfer system (RTS) in 2014. Note: there was a significant difference among 2003, GQS, and RTS at the level of 0.05 .

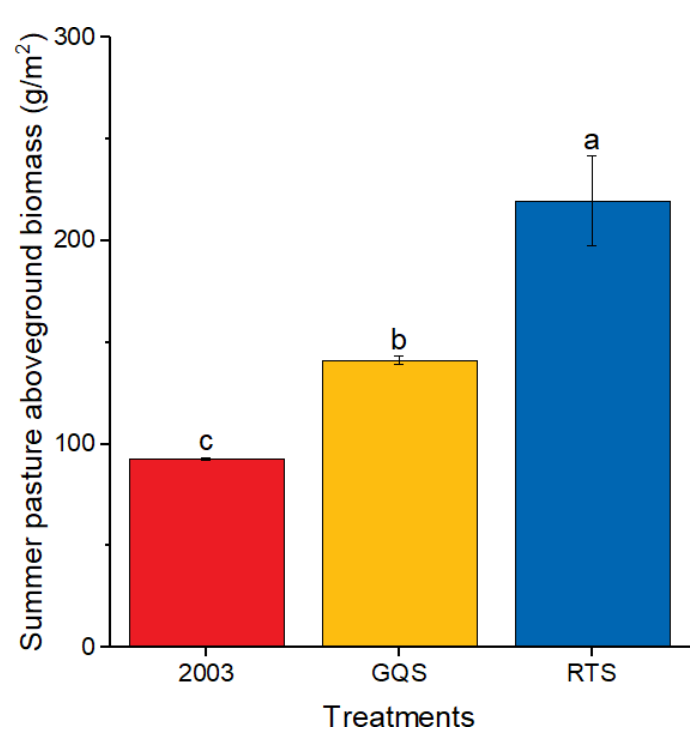

\section{Soil carbon and nitrogen density}

The analyses of carbon density indicate that the level of carbon concentration at $0-10 \mathrm{~cm}$ depth under the GQS is $28.4 \%$ higher than RTS. Similarly, the level of nitrogen density at $0-10 \mathrm{~cm}$ depth under the GQS is $16.3 \%$ higher than RTS (Fig. 4). We also compared soil bulk density, water content, and fractal dimension (Appendix 1, Table A1). Overall, differences in soil bulk density and soil water content were mainly observed at depths of $0-10 \mathrm{~cm}$ in all treatments. Specifically, compared to 2003, soil bulk density at $0-10 \mathrm{~cm}$ depth under the GQS was $17.1 \%$, lower than the baseline $(P<0.05$, whereas it was $22.8 \%$ under RTS, higher than the baseline $(P<0.05)$. Similarly, compared to 2003 , soil water content at the depth of $0-10 \mathrm{~cm}$ under the GQS was $33.8 \%$ higher $(P<0.05=$ whereas only small changes were observed under the RTS $(P>0.05)$. Analysis of soil fractal dimension also demonstrated some differences among the treatments (Appendix 1, Table A2). Compared with 2003, soil fractal dimension under RTS is relatively lower whereas it is a bit higher under GQS in 2014.

Fig. 4. Soil organic carbon density (A) and nitrogen density (B) at $0-10 \mathrm{~cm}$ in the depth of summer pasture at baseline in 2003, and under the community quota system (GQS) and rangeland transfer system (RTS) in $2014(\mathrm{n}=9)$. Note: there was a significant difference among 2003, GQS, and RTS at the level of 0.05 .

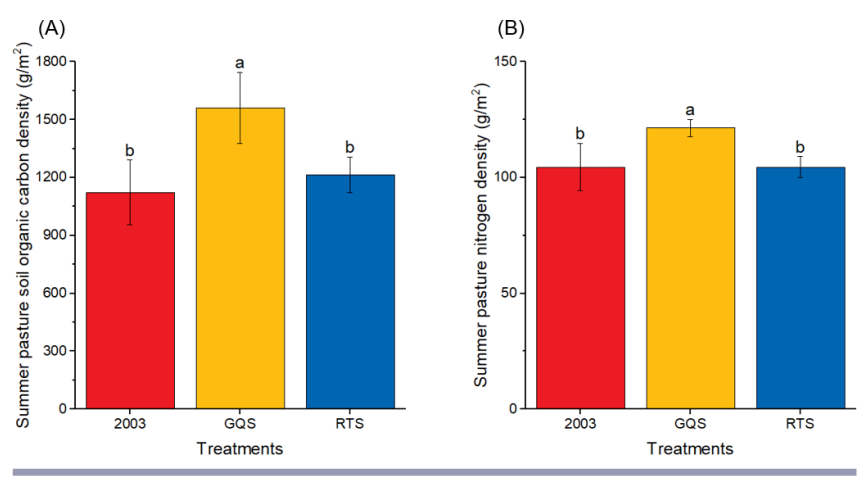

\section{DISCUSSION}

Vegetation composition, aboveground biomass, and soil nutrients were different under the RTS (Village A) and the GQS $(\mathrm{CNH}$ Village) in 2014 and seem to have changed more since 2003 under the RTS. The differences in aboveground biomass found between the GQS and the RTS may be attributed to changes in species composition. Cover of non-palatable forbs and graminoids was highest for the RTS, and aboveground biomass was also higher. Soil properties were also different in the two systems. The findings for soil properties suggest that the different management systems have induced rapid changes in topsoil properties, and that the GQS maintains more preferred rangeland soil conditions while the RTS leads to lower carbon and nitrogen content at $0-10 \mathrm{~cm}$ in depth.

These findings were consistent with herder observations of changes in the rangeland ecosystem. Given the similar climatic 
conditions and socioeconomic conditions between these two villages, we believe that the differences in rangeland ecological conditions were primarily due to the different management institutions deployed and how they facilitate livestock movement over temporal-spatial scales.

The RTS relies on market-based rentals of land to create opportunities for livestock movement among individual grazing parcels to increase mobility, but under the current, short-term rental system, it does not create a shared interest in stewardship of the rented pastures for either the lessee and leaser or for the community. It may increase a certain level of mobility through the use of more than one fenced parcel, but findings from our studies have shown that there is higher grazing pressure on summer pastures due to limited seasonal livestock mobility, and because the tenants have no interest in maintaining pasture conditions. Consequently, the RTS has led to more concentrated and frequent grazing activities on rented grazing parcels and to a longer grazing season, causing changes in vegetation composition and soil structure.

An interview with Mr. JTJ, who has been a shepherd for almost 30 years, from Village A (RTS) states:

\begin{abstract}
In 2008, we had around 14 yaks and 40 sheep. In 2010, we had to sell out all of our livestock because we do not have the money to rent in other grazing areas, and the livestock mortality is high without being able to access other good grazing areas. Therefore, we sold our livestock and rented out our grazing areas to other herders in our village. We can approximately earn an average of $R M B \$ 20,000$ every year from grazing rental, and in each year, we probably rent out our grazing land for 3-4 times with 2-3 months of duration at each rental time. My grazing land used to be very good, but now after renting out to many families, and because many of those families who rented in my land used the grazing area with their maximum capacity, the vegetation conditions have deteriorated rapidly with increased levels of pika and bare ground in my grazing land.
\end{abstract}

Similarly, just as our study found, other studies in the pastoral regions of the Tibetan Plateau have also found that grazing at intense levels (Harris et al. 2016) within individual grazing parcels (Cao et al. 2013, 2018) exerted a negative effect on preferred vegetation and soils (Li et al. 2013, 2017, 2018, Cao et al. 2017). The higher concentrations of grazing and longer grazing periods in summer pastures have been shown to interactively lead to soil degradation (Sparling and Schipper 2004, Li et al. 2013, Wang et al. 2015, Zhuang et al. 2019).

The RTS limits resource access and management at the household scale and does not restore livestock mobility at larger spatialtemporal scales, nor does it create a shared interest in grassland conditions or take advantage of the shared labor and governance traditional to these areas. Thus, it may not be an effective way to address fragmentation of rangeland use.

For example, in an interview with Mr. ZMCR, a male herder from Village A (RTS) stated:

We do not have enough money to rent in grazing areas from other families, and our livestock could not move around in larger areas like before, and increased grazing pressure in our grazing parcel. About 4 years (2011) ago, dum pu go ngön (blue head flower, or Elsholtzia densa Benth) starts to grow in our land, and it expanded rapidly. Livestock don't like to graze on this plant, and sheep get sick if they eat these plants. Now (2014), when I go to herd our livestock, I can see large areas of this plant in almost every hundred steps. I think our rangeland conditions are deteriorating rapidly now.

In addition, the system is costly: shared labor and peer-based enforcement mechanisms are lost, and traditional social relations that facilitated use of common resources are lost.

Given this, we believe that even though RTS restored a certain level of livestock mobility for families who could pay to rent in individual grazing lands, such a management system still restricted livestock mobility within fenced individual grazing parcels without movement in larger areas, and it was not able to re-aggregate individual grazing lands to restore seasonal livestock mobility at the community scale. In addition, the tenants maximized the use of rented-in grazing land because they paid for the land without having the interest to care for the grazing lands. Consequently, we believe that limiting all management and use of rangelands and livestock mobility at the household scale without being able to restore livestock mobility and stewardship at the community scale are the main factors driving higher levels of rangeland degradation under RTS in compare to GQS.

In comparison, the GQS system draws on community customary institutions to manage rangeland resources and livestock mobility at the community scale, while applying a market-based grazing quota allocation to control and allocate livestock use at the household scale. Thus, institutions at two scales interact to offset the impacts of rangeland fragmentation. Community use of rangelands under GQS maintains a flexible pattern of seasonal livestock mobility between the three seasonal pastures, located at different elevations, and greater mobility within seasonal, common pastures. Together, these help to alleviate grazing pressures including livestock trampling effects on rangeland plants and soil (Su et al. 2015, Cao et al. 2017, 2018, Zhuang et al. 2019), which explains the better vegetation composition and soil properties under GQS in our study. We believe that the GQS clarifies herder grazing rights in a way that maintains community collective use of rangelands, preventing fragmentation of rangeland management and maintaining herd access to unevenly distributed heterogenous rangeland resources.

Because biophysical interactions in fields are so complex and play a major role in determining the ecological characteristics of rangelands at larger scales (Harris et al. 2015, Tang et al. 2015, Hopping et al. 2018), using observational methods without experimental studies cannot isolate causative mechanisms. Future studies using experimental methods on the interactions between livestock and rangeland ecosystems at different scales are needed to understand which management systems will be more effective in addressing rangeland fragmentation under climate change and external disturbances (e.g., market forces, social-economic development, and other policies).

\section{CONCLUSIONS}

Different institutional arrangements, operating at different scales, are being practiced in the pastoral regions of the Qinghai-Tibet Plateau as a way of addressing rangeland fragmentation. We show 
that although the level of aboveground biomass is higher in RTS than GQS, the vegetation composition shifted to a dominance of non-palatable forbs and graminoids. In addition, the assessment of topsoil properties demonstrates that RTS grasslands had higher soil bulk density, lower soil fractal dimension, and lower carbon and nitrogen density than the GQS-managed grasslands. The GQS used innovative strategies for clarifying grazing quotas of individuals, so that the pastoral communities were able to maintain community collective use of rangeland with seasonal livestock mobility. Although RTS applied market-based rangeland rental systems to restore a certain level of livestock mobility after division of rangelands to individual households, it does not support the removal of fences to re-aggregate individual grazing parcels. Grazing mobilities remain limited within individual grazing parcels, with more grazing intensity on the rented-in grazing parcels observed. Therefore, we conclude that GQS is more effective in addressing rangeland fragmentation when compared with RTS. However, we also acknowledge that there may be potential place-based biophysical and ecological differences that we were unable to capture in making comparisons of current vegetation conditions in our study sites with the historical data, and thus the causes of different changes in vegetation conditions and soil structures may not be merely attributed to the different management systems.

The findings of this study provide some important lessons for addressing the fragmentation of rangelands in pastoral areas more generally. This is a major challenge for pastoral systems reliant on mobility as a response to uncertain environmental conditions. Our study shows that landscape-scale community responses are essential, and rebuilding or creating institutions that facilitate livestock movement between seasonal pastures to rebuild spatial landscape connectivity is vital (cf. Taylor et al. 1993, McAllister et al. 2006, Galvin 2008). Institutions that enable the use of larger land areas facilitate livestock mobility and subsequently, access to heterogenous rangeland resources increases the capacity of rangelands to produce livestock (Behnke and Scoones 1993). This requires management institutions that operate at a larger community scale than is possible in the rental arrangements seen between households. Our research highlights the importance of alignment across scales (Hobbs et al. 2008). Damaging ecological changes may occur because the temporalspatial and functional use scales at which the interactions between social-ecological systems occur and the scale of institutions responsible for management are misaligned, resulting in socialecological system disruptions, inefficiencies, and loss of important system components (Hobbs et al. 2008); as we observed in the case of the RTS institutional arrangement.

The GQS institutional arrangement offers an innovative solution to a challenge that rangeland management policies face both in China and worldwide: how to overcome the contradiction between establishing a market economy by clarifying property rights through privatization and monetization at the household scale and maintaining community collective use of rangelands to develop larger spatial livestock mobility and resource connectivity to avoid rangeland fragmentation.

Our findings therefore have two important policy implications. First, as China (or indeed any other country) seeks to implement market-based rangeland management policies, to address rangeland fragmentation and sustain mobility, an alignment of scales is crucial, linking household and community scales. This results in improved management and ecological outcomes for rangeland use compared to a rental system focused only on the household scale. Second, rangeland policy should acknowledge and promote local initiatives that restore or sustain livestock movement and shared interests in rangeland conditions at the community scale to address the drawbacks of rangeland fragmentation, and governments should provide more policy space for local communities to organize such innovative rangeland institutions.

Responses to this article can be read online at: https://www.ecologyandsociety.org/issues/responses. php/12326

\section{Acknowledgments:}

This paper was supported by the Natural Science Foundation of China Youth Project (41901241; 71703126), China Postdoctoral Science Foundation (2018M631500), the Fundamental Research Funds for the Central Universities (JBK2101035), and partly supported by project accession No. CA-B-ECO-0117-MS from the USDA National Institute of Food and Agriculture, and European Research Council (ERC) Advanced Grant Project PASTRES project (Pastoralism, Uncertainty \& Resilience: Global Lessons from the Margins; www.pastres.org). We thank all the students in our lab group for their contributions and discussion during our weekly group meeting. And we want to express our deepest gratitude to the local guide and herders who dedicated time and effort to our fieldwork.

\section{Data Availability:}

The datalcode that supports the findings of this study are available on request from the corresponding author [ZMH]. None of the datalcode are publicly available because they contain information that could compromise the privacy of research participants. We declare that all the interviews were conducted with full approval and consent from the interviewees. We use code names for the study sites and for those interviewees whose quotes were directly cited in the paper.

\section{LITERATURE CITED}

Banks, T., C. Richard, P. Li, and Z. L. Yan. 2003. Communitybased rangeland management in Western China: rationale, pilot project experiences, and policy implications. Mountain Research and Development 23:132-140. https://doi.org/10.1659/0276-4741 (2003)023[0132: cgmiwc]2.0.co;2

Bao, S. D. 2000. Soil agricultural chemistry analysis. China Agriculture Press, Beijing, China.

Benke, R., and I. Scoones. 1992. Rethinking range ecology: implications for rangeland management in Africa. Issues Paper No.33. International Institute for Environment and Development (IIED), Dryland Networks Programme, London, UK. [online] URL: https://pubs.iied.org/sites/default/files/pdfs/migrate/7282IIED. pdf 
Cao, J., E. T. Yeh, N. M. Holden, Y. Yang, and G. Du. 2013. The effects of enclosures and land-use contracts on rangeland degradation on the Qinghai-Tibetan Plateau. Journal of Arid Environment 97:3-8. https://doi.org/10.1016/j.jaridenv.2013.05.002

Cao, J., Y. Gong, E. T. Yeh, N. M. Holden, J. F. Adamowski, R. C. Deo, M. Liu, J. Zhou, J. Zhang, W. Zhang, S. Zhang, D. Sheng, S. Yang, X. Xu, M. Li, and Q. Feng. 2017. Impact of grassland contract policy on soil organic carbon losses from alpine grassland on the Qinghai-Tibetan Plateau. Soil Use Management 33:663-671. https://doi.org/10.1111/sum.12387

Cao, J., X. Xu, R. C. Deo, N. M. Holden, J. F. Adamowski, Y. Gong, Q. Feng, S. Yang, M. Li, J. Zhou, J. Zhang, and M. Liu. 2018. Multi-household grazing management pattern maintains better fertility. Agronomy for Sustainable Development 38:6. https://doi.org/10.1007/s13593-017-0482-2

Chen, X., Q. You, F. Sielmann, and N. Ruan. 2017. Climate change scenarios for Tibetan Plateau summer precipitation based on canonical correlation analysis. International Journal of Climatology 37:1310-1321. https://doi.org/10.1002/joc.4778

Chinasho, A., D. Yaya, and S. Tessema. 2017. The adaptation and mitigation strategies for climate change in pastoral communities of Ethiopia. American Journal of Environmental Protection 6 (3):69-74 https://doi.org/10.11648/j.ajep.20170603.12

Dong, Q.-M., X.-Q. Zhao, G.-L. Wu, J.-J. Shi, and G.-H. Ren. 2013. A review of formation mechanism and restoration measures of "black-soil-type" degraded grassland in the Qinghai-Tibetan Plateau. Environmental Earth Sciences 70(5):2359-2370. https:// doi.org/10.1007/s12665-013-2338-7

Fox, J. L., K. Dhondup, and T. Dorji. 2009. Tibetan antelope Pantholops hodgsonii conservation and new rangeland management policies in western Chang Tang Nature Reserve, Tibet: is fencing creating an impasse? Oryx 43(2):183-190. https:// doi.org/10.1017/S0030605308001774

Galvin, K. A., R. S. Reid, R. H. Behnke, Jr., and N. T. Hobbs. 2008. Fragmentation in semi-arid and arid landscapes: consequences for human and natural systems. Springer, Dordrecht, The Netherlands. https://doi.org/10.1007/978-1-4020-4906-4

Gongbuzeren, Y. Li, and W. Li. 2015. China's rangeland management policy debates: what have we learned? Rangeland Ecology and Management 68(4):305-314. https://doi.org/10.1016/ j.rama.2015.05.007

Gongbuzeren, M. Zhuang, and W. Li. 2016. Market-based grazing land transfers and customary institutions in the management of rangelands: two case studies on the QinghaiTibetan Plateau. Land Use Policy 57:287-295. https://doi. org/10.1016/j.landusepol.2016.05.035

Gongbuzeren, L. Huntsinger, and W. Li. 2018. Rebuilding pastoral social-ecological resilience on the Qinghai-Tibetan Plateau in response to changes in policy, economics and climate. Ecology and Society 23(2):21. https://doi.org/10.5751/ES-10096-230221

Gongbuzeren. 2019. Rangeland institutional changes under marketization in the pastoral regions of the Tibetan Plateau. Southwestern University of Finance and Economics Press, Chengdu, China.
Gongbuzeren, and W.-J. Li. 2016. The role of market mechanisms and customary institutions in rangeland management: a case study in Qinghai-Tibetan Plateau. Journal of Natural Resources 31(10):1637-1647

Han, L. Y. 2018. Rangeland logics: survey on rangeland ecosystem and herder livelihood. Ethnic Publishing House, Beijing, China.

Harris, R. B., L. H. Samberg, E. T. Yeh, A. T. Smith, W. Wang, J. Wang, Gaerrang, and D. J. Bedunah. 2016. Rangeland responses to pastoralists' grazing management on a Tibetan steppe grassland, Qinghai Province, China. Rangeland Journal 38 (1):1-15. https://doi.org/10.1071/rj15040

Harris, R. B., W. Wang, Badinqiuying, A. T. Smith, and D. J. Bedunah. 2015. Herbivory and competition of Tibetan Steppe vegetation in winter pasture: effects of livestock exclosure and Plateau pika reduction. Plos ONE 10(7):1. https://doi. org/10.1371/journal.pone.0132897

Hobbs, N. T., K. A. Galvin, C. J. Stokes, J. M. Lackett, A. J. Ash, R. B. Boone, R. S. Reid, and P. K. Thornton. 2008. Fragmentation of rangelands: implications for humans, animals, and landscapes. Global Environmental Change 18(4):776-785. https://doi. org/10.1016/j.gloenvcha.2008.07.011

Hopping, K. A., A. K. Knapp., T. Dorji, and J. A. Klein. 2018. Warming and land use change concurrently erode ecosystem services in Tibet. Global Change Biology 24:5534-5548. https:// doi.org/10.1111/gcb.14417

Jakes, A. D., P. F. Jones, L. C. Paige, R. G. Seidler, and M. P. Huijser. 2018. A fence runs through it: a call for greater attention to the influence of fences on wildlife and ecosystems. Biological Conservation 227:310-318. https://doi.org/10.1016/j.biocon.2018.09.026

Klein, J. A., J. Harte, and X.-Q. Zhao. 2007. Experimental warming, not grazing, decreases rangeland quality on the Tibetan Plateau. Ecological Applications 17:541-557. https://doi. org/10.1890/05-0685

Lai, Y., and W. Li. 2012. Pasture transfer's impact on rangeland ecosystem and pastoralists' livelihoods in arid and semi-arid area: a case study in New Barag Right Banner, Hulunbeir. Resource Science 34:1039-1048

Li, Y., S. Dong, L. Wen, X. Wang, and Y. Wu. 2013. Assessing the soil quality of alpine grasslands in the Qinghai-Tibetan Plateau using a modified soil quality index. Enviromental Monitoring Assessment 185:8011-8022. https://doi.org/10.1007/ s10661-013-3151-1

Li, L., F. E. Fassnacht, I. Storch, and M. Bürgi. 2017. Land-use regime shift triggered the recent degradation of alpine pastures in Nyanpo Yutse of the eastern Qinghai-Tibetan Plateau. Landscape Ecology 32(11):2187-2203. https://doi.org/10.1007/ s10980-017-0510-2

Li, W., and L. Huntsinger. 2011. China's grassland contract policy and its impacts on herder ability to benefit in Inner Mongolia: tragic feedbacks. Ecology and Society 16(2):1. https://doi. org/10.5751/es-03969-160201

Li, A., J. Wu, X. Zhang, J. Xue, Z. Liu, X. Han, and J. Huang. 2018. China's new rural "separating three property rights" land 
reform results in grassland degradation: evidence from Inner Mongolia. Land Use Policy 71:170-182. https://doi.org/10.1016/ j.landusepol.2017.11.052

Li, W. J., and Q. Zhang. 2009. Understanding rangeland challenges: discovery of rangeland use and management issues at arid and semiarid regions. Economic Science Press, Beijing (in Chinese).

McAllister, R. R. J., I. J. Gordon, M. A. Janssen, and N. Abel. 2006. Pastoralists responses to variation of rangeland resources in time and space. Ecological Applications 16:572-583. https://doi. org/10.1890/1051-0761(2006)016[0572:PRTVOR]2.0.CO;2

Ostrom, E. 1990. Governing the commons: the evolution of institutions for collective action. Cambridge University Press, Cambridge, UK.

Qinghai Province Government (QPG). 2011. Qinghai Province Government Standing Committee No 94 Document "Qinghai Province rangeland transfer system". Qinghai Province Government, Xining City, Qinghai Province, China. [online] URL: http://www.china.com.cn/guoqing/zwxx/2012-07/11/ content 25876548.htm

Sang, W. 2009. Plant diversity patterns and their relationship with soil and climatic factors along an altitudinal gradient in the middle Tianshan Mountain area, Xinjiang, China. Ecological Research 24:303-314. https://doi.org/10.1007/s11284-008-0507-z

Scoones, I. 1994. Living with uncertainty: new directions in pastoral development in Africa. Intermediate Technology Publications, London, UK. https://doi.org/10.3362/9781780445335

Scoones, I. 2015. Sustainable livelihoods and rural development: agrarian change and peasant studies. Practical Action Publishing, London, UK.

Sparling, G., and L. Schipper. 2004. Soil quality monitoring in New Zealand: trends and issues arising from a broad-scale survey. Agriculture, Ecosystems and Environment 104:545-552. https:// doi.org/10.1016/j.agee.2003.11.014

State Council. 2008. Perspectives on 2009 stable and sustainable agricultural development. State Council, Beijing, China. [online] URL: http://news.xinhuanet.com/newscenter/2008-10/19/ content 10218932.htm

State Council. 2016. Perspectives on further completion of land contract and management rights in agricultural regions of China. [Translated from the Chinese.] State Council, Beijing, China. [online] URL: http://www.gov.cn/xinwen/2016-10/30/content_5126200. $\underline{\mathrm{htm}}$

Su, X., S. Dong, S. Liu, Y. Wu, H. Zhao, X. Zhang, J. Weng, L. Tang, X. Wu, and P. Hou. 2015. Changes in rangeland cove associated with livestock grazing in Altun National Nature Reserve, northwest Qinghai-Tibetan Plateau. Rangeland Journal 37:97-105. https://doi.org/10.1071/RJ14064

Taylor, P. D., L. Fahrig, K. Henein, and G. Merriam. 1993. Connectivity is a vital element of landscape structure. Oikos 68:571-573. https://doi.org/10.2307/3544927

Tang, L., S. Dong, R. Sherman, S. Liu, Q. Liu, X. Wang, X. Su, Y. Zhang, Y. Li, Y. Wu, H. Zhao, C. Zhao, and X. Wu. 2015. Changes in vegetation composition and plant diversity with rangeland degradation in the alpine region of Qinghai-Tibet Plateau. Rangeland Journal 37:107-115. https://doi.org/10.1071/ $\underline{\mathrm{RJ} 14077}$

Tyler, S. W., and S. W. Wheatcraft. 1989. Application of fractal mathematics to soil water retention estimation. Soil Science Society of America Journal 53(4):987-996. https://doi. org/10.2136/sssaj1989.03615995005300040001x

Ulambayar, T., and M. E. Fernández-Giménez. 2019. How community-based rangeland management achieves postive social outcomes in Mongolia: a moderated meditation analysis. Land Use Policy 82:93-104. https://doi.org/10.1016/j.landusepol.2018.11.008

Wang, Y., G. Herberling, E. Görzen, G. Miehe, E. Seeber, and K. Wesche. 2017. Combined effects of livestock grazing and abiotic environment on vegetation and soils of grasslands across Tibet. Applied Vegetation Science 20:327-339. https://doi.org/10.1111/ avsc. 12312

Wang, X. T., W. Wang, C. Z. Liang, and Z. L. Liu. 2015. Using positive interaction ecology to explain grassland degradation induced by overgrazing (in Chinese). China Science Bulletin 60:2794-2799. https://doi.org/10.1360/N972015-00041

Yan, Z., N. Wu, D. Yehsi, and J. Ru. 2005. A review of rangeland privatization and its implication on the Tibetan Plateau, China. Nomadic Peoples 9(1):31-52. [online] URL: https://case.edu/affil/ tibet/tibetanNomads/documents/AReviewofRangelandPrivatisation_000. pdf

Yang, Y. H. 2008. Carbon and nitrogen storage in alpine grasslands on the Tibetan Plateau. Peking University, Beijing, China.

Yeh, E. T., and Gaerrang. 2011. Tibetan pastoralism in neoliberalising China: continuity and changes in Guoli. Area 43 (2):165-172. https://doi.org/10.1111/j.1475-4762.2010.00976.x

Yeh, E. T., Y. Nyima, K. A. Hopping, and J. A. Klein. 2014. Tibetan pastoralists' vulnerability to climate change: a political ecology analysis of snow storm coping capacity. Human Ecology 42:61-74. https://doi.org/10.1007/s10745-013-9625-5

Zhou, H., X. Zhao, Y. Tang, S. Gu, and L. Zhou. 2005. Alpine grassland degradation and its control in the source region of the Yangtze and Yellow Rivers China. Grassland Science 51 (3):191-203. https://doi.org/10.1111/j.1744-697X.2005.00028.x

Zhuang, M., Gongbuzeren, and W. Li. 2017. Greenhouse gas emission of pastoralism is lower than combined extensive/ intensive livestock husbandry: a case study on the Qinghai-Tibet Plateau of China. Journal of Cleaner Production 147:514-522. https://doi.org/10.1016/j.jclepro.2017.01.126

Zhuang, M., Gongbuzeren, J. Zhang, and W. Li. 2019. Community-based seasonal movement grazing maintains lower greenhouse gas emission intensity on Qinghai-Tibet Plateau of China. Land Use Policy 85:155-160. https://doi.org/10.1016/j. landusepol.2019.03.032

\section{AUTHOR CONTRIBUTIONS}

First and second author contributed equally to the paper.

Editor's note: The author contribution statement was added on 18 May 2021. 


\section{Appendix 1.}

Table A1.1. Soil bulk density and water content of summer pasture in at baseline in 2003, and under the community quota system (GQS) and rangeland transfer system (RTS) in 2014 (different letters significant at $\mathrm{P}<0.05$ within columns) ( $\mathrm{n}=9$ ).

\begin{tabular}{lllll}
\hline \multirow{2}{*}{ Indicator } & \multirow{2}{l}{ Treatments } & \multicolumn{3}{l}{ Soil depth $(\mathrm{cm})$} \\
\cline { 3 - 5 } & & $0-10$ & $10-20$ & $20-30$ \\
\hline \multirow{2}{*}{$\begin{array}{l}\text { Soil bulk density } \\
\left(\mathrm{g} . \mathrm{cm}^{-3}\right)\end{array}$} & 2003 & $0.88 \pm 0.07 \mathrm{~b}$ & $1.07+0.01 \mathrm{a}$ & $1.09 \pm 0.05 \mathrm{a}$ \\
& GQS & $0.73 \pm 0.03 \mathrm{c}$ & $0.96 \pm 0.20 \mathrm{a}$ & $1.06 \pm 0.12 \mathrm{a}$ \\
\multirow{2}{*}{ Soil water content } & RTS & $1.14 \pm 0.08 \mathrm{a}$ & $1.10 \pm 0.05 \mathrm{a}$ & $1.15 \pm 0.02 \mathrm{a}$ \\
$(\%)$ & GQS & $24.82 \pm 0.03 \mathrm{~b}$ & $22.14 \pm 0.02 \mathrm{~b}$ & $19.35 \pm 0.01 \mathrm{~b}$ \\
& RTS & $34.78+0.02 \mathrm{a}$ & $30.59 \pm 0.05 \mathrm{a}$ & $27.99 \pm 0.04 \mathrm{a}$ \\
& & $24.72 \pm 0.05 \mathrm{~b}$ & $21.77 \pm 0.01 \mathrm{~b}$ & $20.57 \pm 0.01 \mathrm{~b}$ \\
\hline
\end{tabular}

Table A1.2. The soil fractal dimension 2003 at $0-10 \mathrm{~cm}$ in depth of summer pasture at baseline, and under the community quota system (GQS) and rangeland transfer system (RTS) in 2014 ( $n=9)$. Note: Different lowercase indicated that there was significant difference among 2003, GQS and RTS at the level of 0.05, and vice versa.

\begin{tabular}{|c|c|c|}
\hline Indicator & Treatments & Soil fractal dimension \\
\hline \multirow{3}{*}{ soil fractal dimension } & 2003 & $2.61+0.29 \mathrm{~b}$ \\
\cline { 2 - 3 } & GQS & $2.70+0.52 \mathrm{a}$ \\
\cline { 2 - 3 } & RTS & $2.43+0.44 \mathrm{c}$ \\
\hline
\end{tabular}

